Jurnal Pemberdayaan: Publikasi Hasil Pengabdian kepada Masyarakat

Vol. 2, No. 3, Desember 2018, Hal. 525-534

ISSN: 2088 4559; e-ISSN: XXXX-XXXX

DOI:

\title{
PROGRAM PEMBERDAYAAN MASYARAKAT DALAM PEMANFAATAN SAMPAH DALAM RANGKA MENUJU BANTUL BERSIH SAMPAH 2019
}

\author{
Soviyah $^{1}$, Amrullah Lamondjong ${ }^{2}$, Risa Arum Kuswandari $^{3}$, Marisa $^{4}$ \\ 1,2,3,4 Universitas Ahmad Dahlan, Jalan Kapas, No 9, Semaki Yogyakarta 55166 \\ Email: soviyah@pbi.uad.ac.id
}

\begin{abstract}
ABSTRAK
Salah satu permasalahan yang ada dimasyarakat Desa Caturharjo, Kecamatan Pandak, Kabupaten Bantul, Yogyakarta adalah banyaknya sampah disekitar lingkungan warga. Sampah sampah ini berupa sampah organik maupun nonorganic. Dengan kuantitas sampah yang cukup banyak menjadikan adanya penumpukan sampah dilingkungan sekitar warga. Program KKN Reguler Periode 65 UAD kali ini difokuskan pada pemberdayaan masyarakat dalam pemanfaatan sampah. Program ini bertujuan memberdayakan masyarakat Desa Caturharjo, Pandak Bantul dalam program pemanfaatan sampah sehingga sampah yang ada di lingkungan warga bisa diubah menjadi barang yang lebih menguntungkan dan tentu saja mengurangi volume sampah itu sendiri. Metode pelaksanaan program KKN regular 65 ini meliputi: pendidikan masyarakat, difusi teknologi dan praktek langsung. Dampak dari kegiatan KKN ini adalah: 1) tercipta kesadaran masyarakat tentang pentingnya PHBS, 2) peningkatan pengetahuan masyarakat dalam mengolah sampah organik dan nonorganik, 3) masyarakat terampil membuat karya kreatif dari plastic, stik es krim dan botol plastik bekas.
\end{abstract}

Kata kunci: pemberdayaan masyarakat, recycle, Bantul Bersih Sampah 2019

\begin{abstract}
One of the problems that exist in the community of Caturharjo Village, Pandak District, Bantul Regency, Yogyakarta is the amount of garbage around the neighborhood. This garbage is in the form of organic and nonorganic waste. With a large amount of waste, there is a buildup of garbage around the community. The UAD 65th Regular KKN Program this time focused on community empowerment in the utilization of waste. The program aims to empower the community of Caturharjo Village, Pandak Bantul in a program to utilize waste so that the waste in the community's environment can be converted into more profitable goods and of course reduce the volume of waste itself. The methods for implementing the regular 65 Community Service Program include: community education, technology diffusion and direct practice. The impacts of the KKN activities are: 1) creating public awareness about the importance of PHBS, 2) increasing community knowledge in processing organic and non-organic waste, 3) the community is skilled in making creative works of plastic, ice cream sticks and used plastic bottles.
\end{abstract}

Keywords: community empowerment, recycle, Bantul Clean Waste 2019 


\section{PENDAHULUAN}

Desa Caturharjo adalah salah satu dari 4 (empat) desa yang ada di Kecamatan Pandak Kabupaten Bantul Daerah Istimewa Yogyakarta. Desa Caturharjo berada pada $12 \mathrm{Km}$ dari Kota Kabupaten Bantul arah barat daya dan merupakan desa yang berada pada paling ujung selatan di wilayah Kecamatan Pandak. Dengan luas wilayah 593.1070 Ha., Desa Catuharjo berbatasan langsung dengan Desa Triharjo, Kecamatan Bambanglipuro di sebelah Timur, Desa Gadingsari, Kecamatan Pandak di sebelah Selatan, dan Desa Trimurti, Kecamatan Srandakan yang berada di sebelah barat Desa Caturharjo. Desa Caturharjo terbentuk dari 4 (empat) kelurahan yaitu Kelurahan Gluntung yang meliputi penukuhan Gumulan, Tegalsempu, dan Tunjungan, kelurahan Tegalayang yang meliputi pendukuhan Krapakan, Samparan, Tegallayang Kulon dan Tegallayang Wetan, serta kelurahan Glagahan yang meliputi pendukuhan Kuroboyo, Glagahan, dan Bogem. Selain 4 kelurahan besar tersebut, terdapat total 77 RT yang ada di wilayah Desa Caturharjo.

Secara geografis, dari segi akses masuk, Desa Caturhajo belum memiliki akses jalan yang bagus dan memadai. Dengan kondisi yang seperti ini, ada sedikit kendala bagi warga jika berniat pergi ke pusat desa. Diperlukan adanya jalan penghubung yang lebih dekat untuk menuju pusat pemerintahan desa (kantor Desa) yang terletak di Padukahan Salaran. Sementara itu, keadaan tanah di Desa Caturharjo sangat subur dan jumlah air cukup memadai bagi kebutuhan warga. Dengan kondisi geografis yang seperti ini, tidak heran jika mayoritas masyarakat Desa Caturharjo bermata pencaharian sebagai petani yang menanam tanaman pangan dan juga menanam serta mengolah tanaman perkebunan.

Meskipun secara kondisi alam warga Desa Caturharjo tidak memiliki banyak kendala, namun bukan berarti tidak ada permasalahan yang ada di Desa Caturharjo. Dari hasil analisis situasi yang dilakukan, ditemukan beberapa permasalahan di Desa Caturharjo, antara lain : 1) banyaknya sampah di sekitar lingkungan, 2) kurangnya kesadaran masyarakat tentang pentingnya PHBS, 3) kurangnya pengetahuan masyarakat dalam memilah sampah organik dan anorgnik, 4) kurangya keterampilan masyarakat dalam memanfaatkan sampah. Dengan teridentifikasinya permasalahan seperti tersebut diatas, sangat penting untuk diadakan program pendidikan dan pengelolaan sampah bagi masyarakat Desa Caturharjo Pandak Bantul. Selain untuk mengurangi volume sampah yang ada, program pemberdayaan pengelolaan sampah akan mendukung program pemerintah Bantul Bersih Sampah 2019.

Peran serta masyarakat dalam pengelolahan lingkungan merupakan kesediaan masyarakat untuk membantu berhasilnya program pengembangan pengelolaan lingkungan 
sesuai dengan kemampuan setiap orang tanpa mengorbankan kepentingan diri sendiri. Tanpa adanya peran serta masyarakat semua program pengelolaan persampahan yang direncanakan akan sia-sia. Salah satu pendekataan masyarakat untuk dapat membantu progam pemerintahan dalam keberhasilan adalah membiasakan pada tingkah laku yang sesuai dengan program persampahan yaitu merubah persepsi masyarakat terahadap peneglolaan sampah yang tertib, lancar dan merata, merubah kebiasaan masyarakat dalam penglolaan sampah yang kurang baikdan fakto-faktor sosial, struktur dan budaya setempat (Wibowo dan Djajwinata, 2004). Menurut Syafrudin (2004), salah satu alternatif yang bisa dilakukan adalah melaksanakan program pengelolahaan sampah berbasis masyarakat seperti minimalisasi limbah dan melaksanakan 5R (Reuse, Recycling, Recovery, Replacing, dan Refilling).

Berdasarkan permasalahan tersebut, maka dipilihlah tujuan program KKN regular 65 UAD kali ini yaitu memperdayakan masyarakat Desa Caturharjo dalam program pemanfaatan sampah dan kepedulian masyarakat terhadap lingkungan dalam rangka mendukung program Bantul Bersih Sampah 2019.

\section{METODE}

Dalam mencapai tujuan yang diharapkan, program KKN regular 65 UAD di Desa Caturharjo dilakukan dengan pemberdayaan masyarakat melalui pemanfaatan sampah yang terbagi menjadi 3 bagian yaitu pendidikan masyarakat, difusi ilmu pengetahuan dan teknologi dan praktek langsung. Ringkasan metode pelaksaan beserta jam kerja efektif mahasiswa (JKEM) tersaji pada table I dibawah ini:

Tabel 1. Metode, Kegiatan, JKEM dan Keterlibatan Mahasiswa

\begin{tabular}{|c|c|c|c|c|}
\hline No. & Metode & Kegiatan & JKEM & $\begin{array}{c}\text { Mahasiswa } \\
\text { vang terlibat }\end{array}$ \\
\hline 1. & $\begin{array}{l}\text { Pendidikan } \\
\text { Masyarakat }\end{array}$ & $\begin{array}{l}\text { 1. Menyelenggarakan Penyuluhan } \\
\text { Kesehatan Lingkungan } \\
\text { 2. Menyelenggarakan penyuluhan } \\
\text { dan praktek PHBS tentang cuci } \\
\text { tangan }\end{array}$ & $\begin{array}{l}1 \times 2 \text { jam } \\
3 \times 1 \text { jam }\end{array}$ & $\begin{array}{l}18 \\
27\end{array}$ \\
\hline 2. & Difusi IPTEK & $\begin{array}{l}\text { 1. Menyelenggarakan Pelatihan } \\
\text { Pembuatan Kompos }\end{array}$ & $1 \times 2$ jam & 27 \\
\hline 3. & $\begin{array}{l}\text { Praktek } \\
\text { Langsung }\end{array}$ & $\begin{array}{l}\text { 1. Pelatihan Pembuatan Pengolahan } \\
\text { Sampah dari Stik Es Krim } \\
\text { 2. Pelatihan Pembuatan Bunga dari } \\
\text { plastik Bekas } \\
\text { 3. Pelatihan Pembuatan Vas Bunga } \\
\text { dari Bahan Botol Plastik Bekas }\end{array}$ & $\begin{array}{l}1 \times 2 \text { jam } \\
1 \times 2 \text { jam } \\
1 \times 2 \text { jam }\end{array}$ & $\begin{array}{l}9 \\
9 \\
9\end{array}$ \\
\hline
\end{tabular}




\section{HASIL, PEMBAHASAN, DAN DAMPAK}

Kelurahan Caturharjo merupakan salah satu kelurahan yang ada di Kecamatan Pandak, Kabupaten Bantul. Wilayah kelurahan Caturharjo ini mempunyai batas wilayah dengan empat desa yaitu sebelah utara berbatasan dengan Desa Triharjo kecamatan Pandak, timur berbatasan dengan Desa Sidomulyo Kecamatan Bambanglipuro, selatan berbatasan dengan Desa Murtigading Kecamatan Sanden, dan barat berbatasan dengan Desa Trimurti Kecamatan Srandakan. Secara geografis, Desa Caturharjo dibagi menjadi 14 (empat belas) pedukuhan, antara lain:

1. Banyuurip

2. Gluntung Lor

3. Gluntung Kidul

4. Gumulan

5. Tegalsempu

6. Tunjungan

7. Krapakan

8. Samparan

9. Tegallayang IX

10. Tegallayang $X$

11. Kuroboyo

12. Korowelang

13. Galagahan

14. Bogem

Luas wilayah Desa Caturharjo adalah 575.36 Ha. Dari luas total ini, yang digunakan sebagai pemukiman seluas 154.54 ha, pertanian seluas 175.18 ha, pusat pemerintahan seluas 0.53 ha, perdagangan dan jasa seluas 0.89 ha, fasilitas seluas 2.19 ha, tempat ibadah seluas 1.27 ha, makam dan lapangan seluas 3.37 ha, kebun seluas 148.58 ha, ladang seluas 32.78 ha dan luas prasarana umum lainnya 56.03 ha.

Sementara dari sisi demografis, jumlah penduduk di Desa Caturharjo sebanyak 11.217 jiwa yang terdiri dari 5.507 penduduk laki-laki dan 5.710 penduduk perempuan. Komposisi penduduk berdasar jenis kelamin dan persentasinya dapat dilihat gambar 1 berikut ini. 


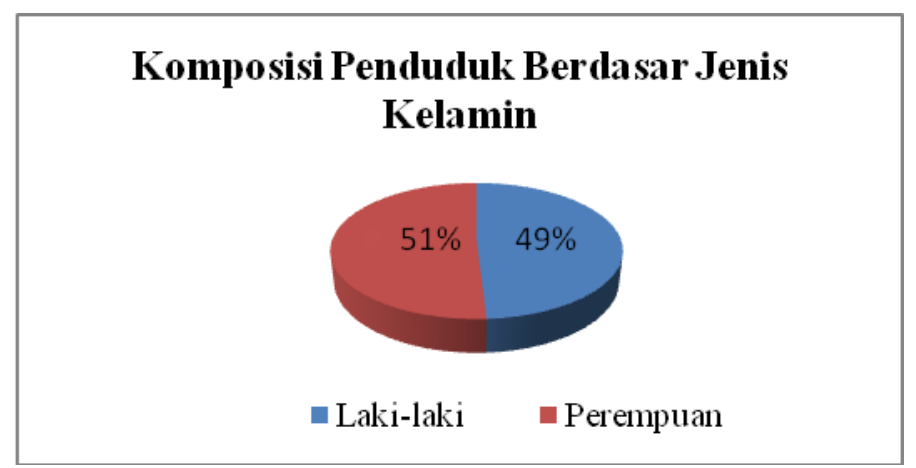

Gambar 1. Komposisi Penduduk Berdasarkan Jenis Kelamin

Dilihat dari pendidikan, komposisi penduduk berdasarkan pendidikan formal adalah sebagai berikut: pendidikan SD sederajat sebanyak 2445 jiwa, pendidikan SMP sederajat sebanyak 1304 jiwa, pendidikan SMU/SMK sebanyak 2590 jiwa dan S1 sebanyak 481 jiwa. Komposisi penduduk berdasarkan pendidikan formal dan presentasinya dapat dilihat dalam gambar 2.

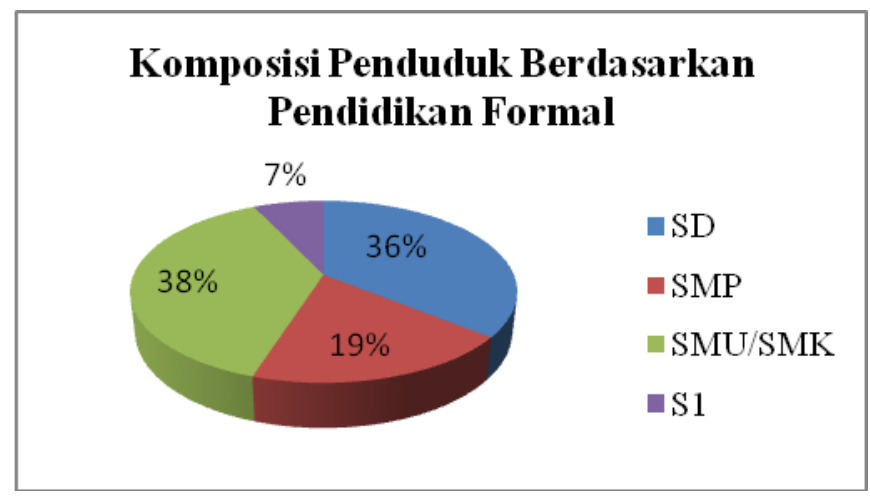

Gambar 2. Komposisi Penduduk Berdasarkan Pendidikan Formal

Sementara dari segi mata pencahariannya, sebanyak 927 orang berprofesi sebagai petani, 1844 orang sebagai buruh, 395 orang bekerja di area perkebunan, 482 orang bekerja di area peternakan, dan 708 orang di area perdagangan/dagang. Selain itu terdapat 416 orang sebagai pegawai negeri, 614 orang sebagai pegawai swasta, dan 178 orang bekerja di area industri rumah tangga. Rangkuman dari komposisi penduduk berdasar mata pencaharian dan persentasinya ini dapat dilihat dalam gambar 3 dibawah ini: 


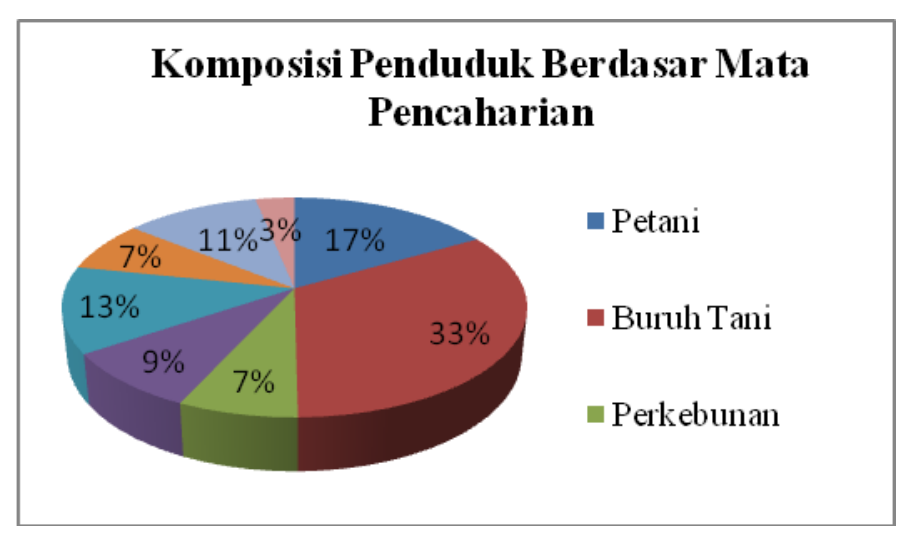

Gambar 3. Komposisi Penduduk Berdasar Mata Pencaharian

Dari segi area kerja program KKN regular 65 kali ini terdapat 3 dusun yang dijadikan focus program. Pertama adalah Dusun Gumulan. Dusun ini terletak diperbukitan tepatnya pada 27 meter diatas permukaan laut.Terdiri dari 10 RT dengan luas wilayah sekitar 87 ha.Terdiri dari 50 ha tanah pertanian 37 ha tanah pemukiman/bangunan penduduk dan $3.5 \mathrm{~km}$ merupakan jalanan yang ada di Dusun Gumulan. Jarak Dusun Gumulan ke kota kecamatan sekitar 1 km, jarak Dusun Gumulan ke kota kabupaten sekitar 12 k sedangkan jarak Dusun Gumulan ke Provinsi sekitar $45 \mathrm{~km}$. Komposisi penduduk berdasarkan agama di Dusun Gumulan mayoritas penduduknya beragama Islam.Tradisi budaya local yang masih berkembang di Dusun Gumulan yaitu upacara adat.Sedangkan untuk kesenian di Dusun Gumulan yaitu Karawitan.

Dusun kedua adalah Pedukuhan Banyuurip. Dusun ini memiliki luas keseluruhan 27 ha. Penduduknya berjumlah 122 KK dengan mata pencaharian masyarakat cukup beragam, akan tetapi yang lebih dominan adalah sebagai petani dan peternak. Sedangkan yang lain bermata pencahariansebagai pegawai baik swasta maupun negeri. Sedangkan dari tingkat pendidikan meskipun masyarakat Pedukuhan Banyuurip sudah cukup sadar dengan program pendidikan 9 tahun, namun masih ada banyak penduduk yang tidak menyekolahkan anaknya ke jenjang pendidikan yang lebih tinggi.

Dusun terakhir adalah Dusun. Dusun Glagahan memiliki luas kurang lebih 36.95 Ha atau 6.4\% dari luas wilayah Desa Caturharjo. Pedukuhan Glagahan terbagi dalam 4 wilayah Rukun Tetangga/RT. Berdasarkan hasil pemetaan swadaya tahun 2014 jumlah penduduk Padukuhan Glagahan berjumlah kurang lenih 629 jiwa dengan $360 \mathrm{KK}$ atau sekitar 6\% dari jumlah penduduk Desa Caturharjo. Jumlah penduduk usia produktif mencapai 339 jiwa atau $54 \%$ dari total jumlah penduduk Padukuhan Glagahan dan 3.1\% dari total jumlah penduduk di Desa caturharjo. Sebagian penduduk di Padukuhan Glagahan mata pencaharian mereka 
lebih banyak sebagai petani ketimbang pegawai negeri maupun swasta. Fasilitas dan aktivitas kegamaan di Dusun Glagahan, Desa Caturharjo, Kecamatan Pandak, Kabupaten bantul: memiliki 1 Masjid dengan nama Masjid Ainun Jariyah dan 1 Mushola dengan anam Mushola Luqman, majelis pengajian rutin bapak-bapak, ibu-ibu dan TPA. Pengajian lapanan yang diadakan setiap selasa malam, pengajian ibu-ibu dilaksanakan setiap malam kamis dan pengajian yasinan setiap malam jumat dilaksanakan secara bergiliran tempat.Aktivitas pelayanan kesehatan yang ada yaitu posyandu yang dilaksanakan setiap bulan sekali.

\section{Gambaran Pelaksanaan}

Beberapa ilustrasi dalam bentuk foto berikut ini menunjukkan aktivitas mahasiswa KKN regular 65 UAD dan warga masyarakat Desa Caturharjo dalam program pemanfaatan sampah:

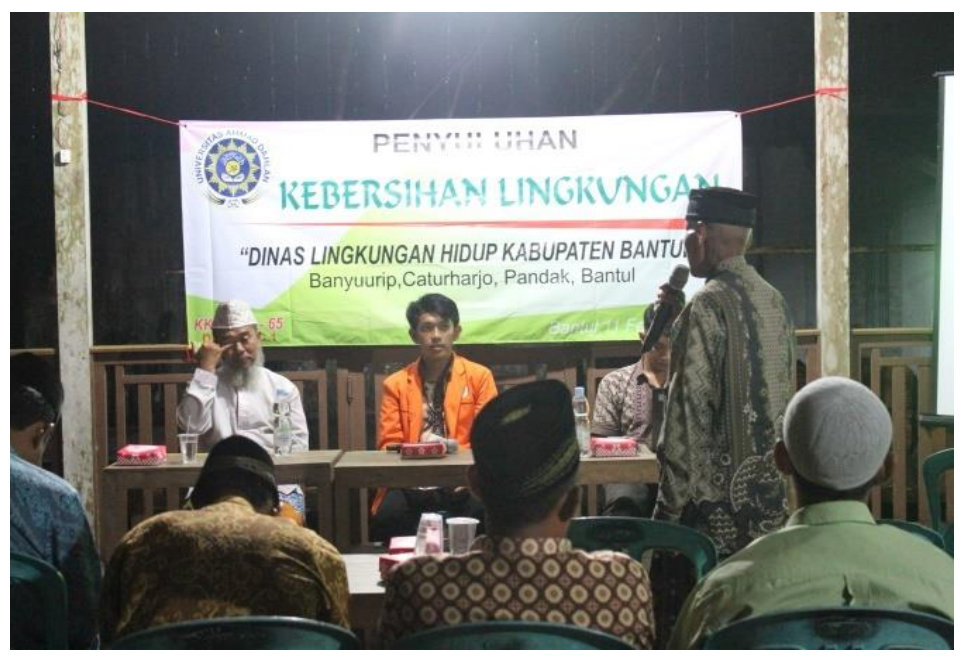

Gambar 4. Program Sosialisasi dan Penyuluhan Kesehatan Lingkungan serta PHBS

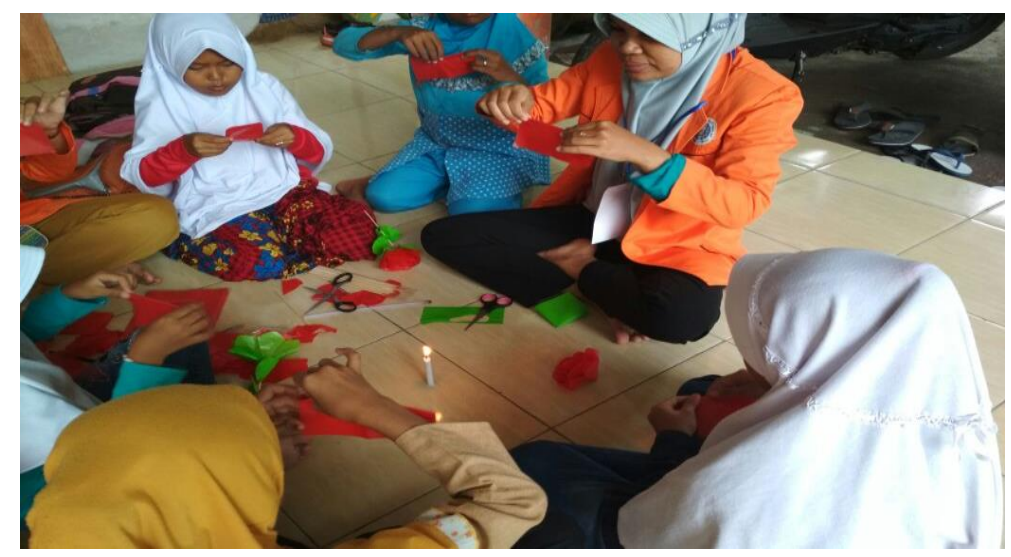

Gambar 5. Pelatihan Pembuatan Bunga dari Sampah Plastik 


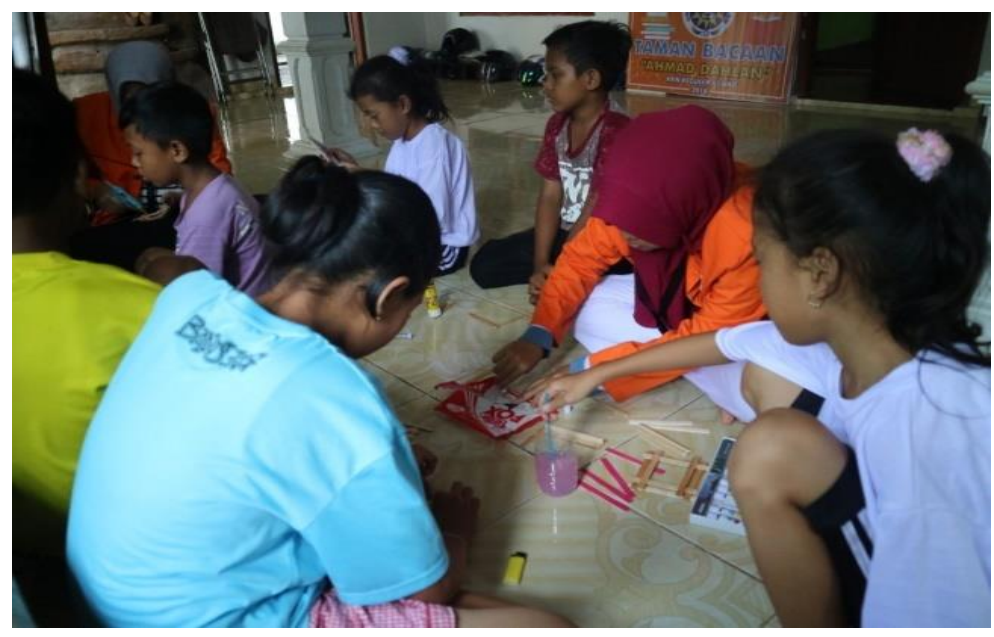

Gambar 6. Pelatihan Pemanfaatan Sampah Plastik

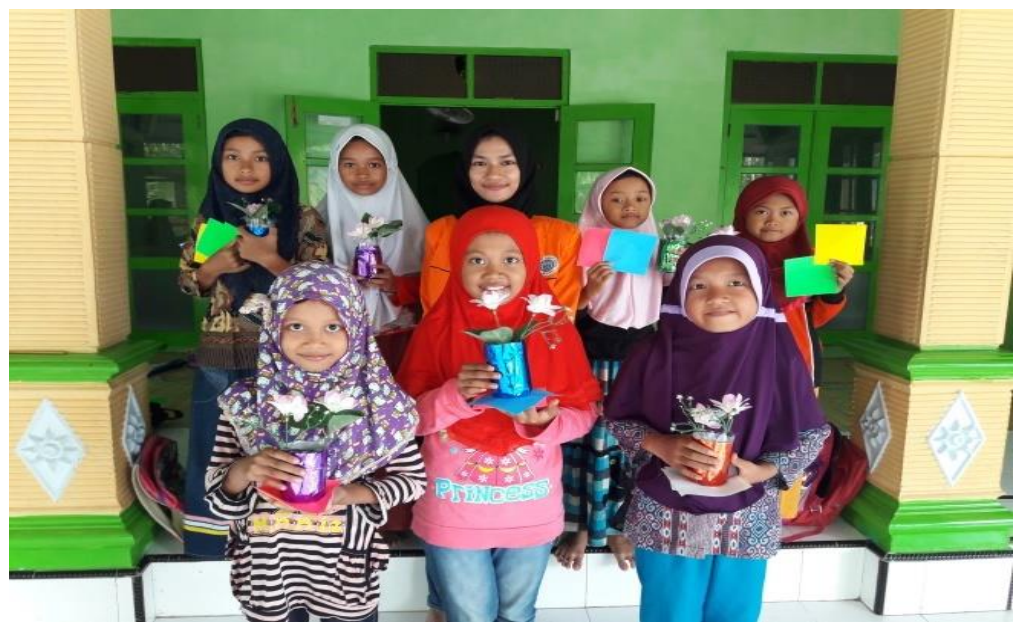

Gambar 7. Pelatihan Pembuatan Bunga dan Vas dari Sampah Plastik

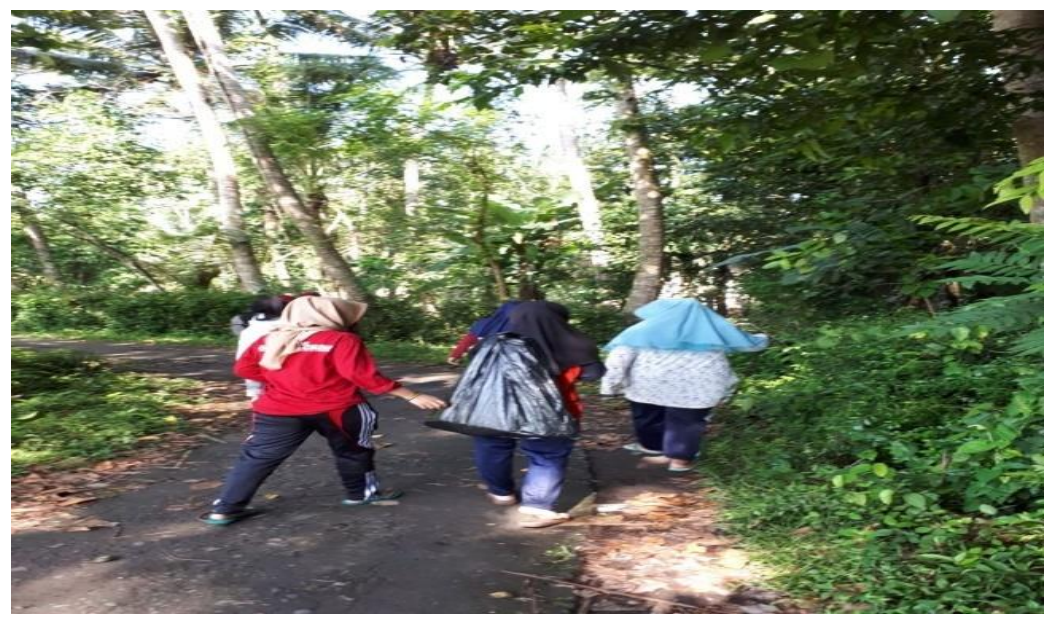

Gambar 8. Pelaksanaan Program Caturharjo Bersih 
Dari gambar-gambar di atas tampak keseluruhan program KKN regular 65 UAD yang dilaksanakan di Desa Caturharjo dapat terlaksana dengan baik. Hal ini berkat pertisipasi masyarakat yang cukup tinggi. Dengan kata lain, mahasiswa KKN regular 65 UAD mampu memberdayakan masyarakat terutama dalam program- pengelolaan dan pemanfaatan sampah. Sementara itu, terkait dampak yang dihasilkan, melalui interview informal yang dilakukan, di dapatkan informasi tentang dampak $\mathrm{KKN}$ regular 65 sebagai berikut:

1. Terciptanya kesadaran masyarakat tentang pentingnya menjaga lingkungan agar tetap bersih dan sehat

2. Adanya kesadaran masyarakat tentang pentingnya PHBS

3. Adanya kesadaran masyarakat tentang pengolahan limbah sampah menjadi sebuah karya kreatif dan bermanfaat

4. Peningkatan pengetahuan masyarakat dalam mengolah sampah

\section{SIMPULAN}

Program KKN UAD dalam memberdayakan masyarakat Desa Caturharjo terhadap kepedulian lingkungan dan pemanfaatan sampah telah berjalan dengan baik. Dibutuhkan adanya program-program yang sejenis agar program pemerintah Bantul Bersih Sampah 2019 dapat terwujud.

\section{DAFTAR PUSTAKA}

Syafrudin. (2004). Pengolahan Sampah berbasis Masyarakat Prosiding, Diskusi Interaktif Pengolahan Sampah Terpadu. Semarang: Program Magister Ilmu Lingkungan Universitas Diponegoro,.

Wibowo A dan Djajawinata D.T. (2004). Penanganan Sampah Perkotaan Terpadu. Diakses tanggal 4 Desember 2016 pada halaman www.kkpi.go.id. 
